\title{
New law is overdue
}

\section{Munich}

A WEST German court last week ordered Hoechst AG to cease construction of a nearly completed plant that would use genetically engineered bacteria to make human insulin. The court ruled that it could not approve the licence granted for the construction of the plant because there is no legal basis for regulating the use of genetic engineering. The decision increases the already intense pressure on the government to pass a law regulating genetic engineering in factories and laboratories.

The court rejected the relevance of the West German Federal Emission Protection Act, which had been used as a legal basis for constructing at least one other facility using genetic engineering. The decision reversed earlier rulings by lower courts which had upheld Hoechst's right to build the plant despite legal challenges from local residents. Hoechst may appeal to the federal constitutional court at Karlsruhe for a reversal of the decision on constitutional grounds, but has not yet decided if it will do so.

The Hoechst plant would use the bacteria Escherichia coli to produce human insulin, as US companies have been doing for a decade. Hoechst has invested an estimated $\$ 60$ million in the plant and a spokeswoman said that the company intends to "fight further" for the use of genetic engineering in drug manufacture in West Germany. She called it "astounding" that there could be so much fuss over a technique that uses $E$. coli, which is found in the human intestine.

But the debate over genetic engineering here has been marked by the almost religious belief held by opponents that all gen- etic engineering is hazardous. Although declining to rule on ethical or safety aspects, the court seemed to agree, saying that genetic engineering represented a "new dimension and quality" of technology with "risks for human beings and the environment that could not be properly assessed at this time . . .. Only the democratically elected legislature" can decide how genetic engineering could be regulated.

The court's decision adds urgency to efforts to speed passage of a 'basic law' for genetic engineering that has been under discussion all year (see Nature 340, 85; 1989). The cabinet published its views on the latest version of the law on 9 November, the day after the court decision, preparing the way for discussion in the Bundestag this week.

It made some concessions to the Länder (states), for example agreeing to more public participation in the licensing procedure, but rejected the request of the Länder that they be allowed to carry out the provisions of the new law. The cabinet warned that this could potentially lead to a variety of interpretations of the law, which would be bad both for industry and for basic research.

But before the law can be put into practice, detailed regulations must be drawn up by the Health Ministry and the regulations attached to the law are "as important as the law itself" for basic research, said Ernst-Ludwig Winnacker, vice-president of the Deutsche Forschungsgemeinschaft (DFG). The effect on basic research "will depend on the wording", he said, and DFG, which is the main source of outside funding for basic research at universities, has volunteered to help draw them up.

Steven Dickman

\section{Approval for TPA competitor}

\section{Washington}

THE approval of SmithKline Beecham's blood-clot-dissolving drug Eminase by the blood and blood products committee of the Food and Drug Administration (FDA) on 31 October puts the drug just one step away from being released for sale on the US market. Eminase, a complex of the already available thrombolytic drug streptokinase with human plasminogen, had been expected to win approval several months ago, but was held up for additional scrutiny by an FDA advisory committee amid reports of pressure from Genentech, which manufactures the rival drug Activase (tissue plasminogen activator, TPA).

David Stump, Genentech's director of clinical research, reported to the advisory committee that he had evidence of antibody production in response to the plasminogen portion of Eminase.

But the results presented by SmithKline Beecham indicated no evidence of increased autoimmunity. Alan Wachter, manager of scientific information at SmithKline Beecham, emphasized that the approval of Eminase was unanimous. Although no price has yet been set, the company says the drug will be cheaper than existing thrombolytic drugs. Eminase has a longer half-life in the bloodstream than streptokinase, and can therefore be administered in 2-5 minutes instead of being infused over an hour. Activase has to be given over a period of three hours.

A large mortality study comparing the efficacy of Eminase, streptokinase and Duteplase (Boroughs Wellcome's TPA) is in progress and results are expected within the next few years. Dlane Gershon

\section{Political pressure} means poor research

\section{Washington}

IN a report issued last week, the Institute of Medicine (IOM) called on the NIH to coordinate vigorous research programmes in basic reproductive biology and in the technologies of medically assisted conception in order to improve the practice of in vitro fertilization (IVF) and embryo transfer in the United States. Neglect of research in this politically sensitive area, the report says, is slowing the development of better methods of contraception, better techniques to preserve endangered species and more cost-effective methods of food production.

At present, embryo and fetal research require the approval of the government's Ethics Advisory Board (EAB). But the board has has not been reconstituted since its charter expired in 1980 . The IOM report complains that the eight-year-old ban on the use of federal funds for this kind of research means that more is now known about reproduction in commercially valuable animals such as cattle than in humans. Moreover, the clinical practice of IVF and embryo transfer is outstripping its scientific foundations.

After the renewal two weeks ago of the ban on research involving the transplantation of fetal tissue into humans (see Nature 342,$105 ; 1989$ ), there is little optimism that any steps will be taken to revive the EAB. The IOM recommends that if politics paralyses the existing review mechanisms, then a nongovernmental organization, along the lines of Britain's Voluntary Licensing Authority, should be established to develop guidelines for embryo and fetal research.

But in addition to the political pressures, the report says that the lack of vocal advocacy groups to fight for major increases in federal support, the lack of communication between researchers in the different fields of reproductive biology and the lack of research material for experiments in humans and other primates all contribute to the slow progress in this field and to the low success rates of IVF and embryo transfer.

To improve the safety and effectiveness of the techniques used, the IOM suggests that the professional societies should establish a mechanism to collect and monitor data from clinical centres.

Christine McGourty

\section{World map answers}

Answers to NGS map questions (page 216). United States (15), Soviet Union (27), Central America (36), Japan (17), Canada (10), France (14), Persian Gulf (3), Mexico (21), Italy (1), Sweden (43), United Kingdom (5), South Africa (16), West Germany (6), Pacific Ocean (30), Egypt (13), Vietnam (7). 